\title{
Central placenta previa with placenta percreta partially invading bladder: a case report
}

\author{
Hasina Banu*, Ju Wen Hui, Li Hui, Liu Hua
}

Department of Gynecology \& Obstetrics, Jingzhou Central Hospital, Affiliated to Yangtze University, Medical College, Jingzhou-434023, Hubei Province, P.R., China

Received: 07 March 2015

Revised: 09 March 2015

Accepted: 19 April 2015

\section{*Correspondence: \\ Dr. Hasina Banu, \\ E-mail: drbanuh@gmail.com}

Copyright: ( $)$ the author(s), publisher and licensee Medip Academy. This is an open-access article distributed under the terms of the Creative Commons Attribution Non-Commercial License, which permits unrestricted non-commercial use, distribution, and reproduction in any medium, provided the original work is properly cited.

\begin{abstract}
Placenta previa, placenta accreta, increta and percreta are increasing day by day due to increased number of cesarean sections now days, but central placenta previa with placenta percreta invading bladder is a very rare obstetrical complication. A case of central placenta previa with placenta percreta partially invading bladder in woman who was G2P1L1 with $32+6$ weeks of gestation and with history of previous cesarean section is presented in this manuscript. The patient was managed with intrapartum cesarean hysterectomy with bilateral ureter $\mathbf{J}$ stents and bladder repair following cesarean delivery of a preterm baby. Total estimated blood loss was $6000 \mathrm{~mL}$. The patient was discharged on $28^{\text {th }}$ December 2014 that is $29^{\text {th }}$ day of admission with a healthy baby. The aim of this study is to bring awareness of such case and to discuss the risk factor, presentation, diagnosis, management and choice of anesthesia for the same.
\end{abstract}

Keywords: Cesarean hysterectomy, Placenta previa, Placenta percreta invading bladder, Subtotal hysterectomy

\section{INTRODUCTION}

Placenta previa means implantation of placenta in the lower segment of uterus in relation to the cervix, while placenta percreta can be defined as invasion of extravillous trophoblast beyond the full thickness of the myometrium and possibly into other intra-abdominal organs, usually the bladder. ${ }^{1-3}$ The placenta under normal pregnancy attaches to the decidual endometruim, a layer of stroma called Nitabuch's layer formed during pregnancy under influence of progesterone. ${ }^{4}$ This layer controls the invasion of extravillious trophoplast of the placenta such that the trophoplast adhere only to the Nitabuch's layer and not into the myometrium. ${ }^{5}$ This layer allows the separation of placenta from the uterine wall by sharing an action between the contracting myometrium and the none contracting placenta. The patients who have absence or deficiency of Nitabuch's layer usually have a complicated surgical course with a mortality rate of $5.6 \%$ to $10 \%$ secondary to hemorrhage, infection. $^{2,6}$ Placenta percreta invading bladder is extremely rare with an incidence of 0.3 to 1 per 10000 births. ${ }^{6}$ Previous cesarean scar with placenta previa is a known risk factor for the placenta percreta; therefore when there is a diagnosis of placenta previa with a history of previous cesarean section, there should be a high suspicion for placenta accreta, increta or percreta. The aim of this study is to bring awareness of such case and to discuss the risk factor, presentation, diagnosis, management and choice of anesthesia for the same.

\section{CASE REPORT}

A 28 years old woman, G2P1L1 was admitted to the obstetric department of Jinzhou Central Hospital on November 29, 2014 with the diagnosis of $32+6$ weeks of gestation with central placenta previa and ployhydraminios for close observation. She gave a 
history of per vaginal spotting 2 days back which subsided spontaneously without any treatment. The patient was stable except mild pale. Per abdominal examination: Fundal height was $30 \mathrm{~cm}$, circumference of abdomen was $103 \mathrm{~cm}$ with fetal position left anterior occipital with floating head and heart rate was 140 beats/minute. There was no leaking or bleeding on genital examination. Ultrasound revealed biperital diameter $88 \mathrm{~mm}$, femoral length $66 \mathrm{~mm}$, amniotic fluid index 10.2 $\mathrm{cm}$ with placenta anterior in relation to the uterus and was completely occupying the cervix. Her hemoglobin at presentation was $107 \mathrm{~g} / \mathrm{L}$ and blood coaguable profile was in normal range.

On $7^{\text {th }}$ December ultrasound was repeated to see fetal profile, which revealed anterior placenta with completely covering cervix. The boundary between the placenta and myometrium was not clear and there was convex hyper echoic area on the surface of bladder hence colour Doppler study was carried out which further revealed blood flow in the myometrium and to the convex area of hyper echoic region on bladder, indicating placenta percreta invading the bladder. The gestational age was 34 weeks which was equal to clinical gestation age with fetal heart rate of 140 beats per minute. The patient and the fetus were stable so we planned for elective cesarean section at 36 weeks.

On $19^{\text {th }}$ December 2014 at mid night, the patient had frequently scar tenderness and gross hematuria with per vaginal bleeding hence we planned for emergency cesarean section under spinal anesthesia after counseling the patient regarding the possibility of excessive bleeding, needing for cesarean hysterectomy. After opening the abdominal cavity there was prominent tortuous blood vessels on the uterus and communicating with the bladder (figure: 1)indicating placenta invading the bladder hence, uterine incision was made a little higher than the previous scar. The placenta had to be cut through to enable the delivery of a preterm baby with APGAR scores of 9,10 , and 10 at 0,5 and 10 minutes of delivery respectively. After which, there was profuse bleeding and was difficult to control by conservative management so spinal anesthesia was converted to general anesthesia to maintain airway, breathing and circulation and subtotal hysterectomy with placenta in situ was performed, after ligation of upper pedicles, an attempt was made to mobilize the bladder. There was no clear cleavage between the bladder and the uterus. Both uterine vessels were ligated and immediate urologist surgeon was consulted and he performed emergency cystoscopy. The cystoscopy revealed edematous bladder wall with bilateral ureter thickening and congestion. Bilateral $\mathbf{J}$ stent was placed in ureter and the adherent portion of bladder was dissected slowly and steadily along with the uterus. The bladder was then repaired after which pelvic drain and an indwelling three way urethral catheter was placed. During the operation, the total blood loss was estimated to be about $6000 \mathrm{ml}$. A total of 3800 $\mathrm{ml}$ red blood cells, $2200 \mathrm{ml}$ of fresh frozen plasma and 20 units' of cryoprecipitate were transfused and a broad spectrum intravenous antibiotic was also injected. The patient regained consciousness after extubation and was transferred to intensive care unit for close observation. The uterus with placenta was sent for histopathological examination, which revealed placenta percreta partially invading the bladder.

On $20^{\text {th }}$ December in ICU, blood tests, renal function test, blood coaguable profile were repeated which were with in normal range except $\mathrm{HgB}$ : $90 \mathrm{~g} / \mathrm{L}$. Ultrasound showed small clots in bladder with no intraperitoneal bleeding or collection. Echocardiogram was also done which showed the presence of bilateral arterial enlargement with mild aterioventricular valve regurgitation hence, an extra two units of red blood cell was transfused.

On $21^{\text {st }}$ December, the patient was stable so transferred back to obstetric department and the very next day indwelling catheter was removed. There was $7 \mathrm{ml}$ of clear urine output and patient passed urine herself without any difficulty. Urine test was send which reveled protein,$+ 2+$ occult blood and the patient was discharged on $28^{\text {th }}$ December 2014.The duration of hospital stay was 29 days and ureteral stents were removed on one month later.



Figure 1: A case of placenta percreta showing prominent tortuous blood vessels on the uterus and communicating with the bladder, indicating placenta invading the bladder.

\section{DISCUSSION}

Central placenta previa with placenta percreta invading bladder is a very rare obstetrical conditions, accounting for $0.3 \%$ to 1 per 10000 births with a mortality rate of 5.6 to $10 \%$ secondary to hemorrhage, infection and damage to adjacent organs. ${ }^{2,6}$ Early diagnosis and timely management is crucial for reducing morbidity and mortality rate.

Placenta percreta is described as abnormal invasion of extravillous trophoblast beyond the full thickness of the myometrium and possibly into other intra abdomen organs, usually the bladder. ${ }^{2,3}$ It is most severe and life 
threatening condition. The literature review suggests that the incidence of placenta percreta is increasing secondary to certain risk factors. These risk factors are increased maternal age during pregnancy, multiple pregnancies, previous cesarean deliveries, myomectomy, previous curettages, Asherman syndromes, use of cocaine; smoking and presence of placenta previa. $^{2}$ These risk factors are all associated with the generalized effect of endometrial injury leading to endometrial atrophy. Clark et al. found an increased association of placenta acreta with history of lower cesarean sections. ${ }^{7}$ The patients in this case study was presented with a risk factor of previous cesarean delivery.

The early sign and symptoms of placenta percreta are none specific and may not be found until events such as antepartum hemorrhage or uterine rupture. ${ }^{8,9}$ The patient in this case report had no symptoms as discussed earlier except for ployhydramnios on presentation but later she developed antepartum hemorrhage and gross hematuria.

The diagnosis of placenta accreta, increta, percreta and placenta previa can be done easily with ultrasound, but the correct diagnosis of placenta percreta invading bladder can be quite difficult. It requires accurate ultrasound interpretation and colour Doppler study. The diagnosis relies heavily on ultrasound, colour Doppler study, MRI and potentially depends on intraoperative evaluation. MRI is considered sensitive diagnostic tool for diagnosis of placenta accreta, increta and percreta, ${ }^{10}$ but failure of MRI to diagnose all cases has also been established. $^{11}$

The management of placenta percreta invading bladder is a team work. A multidisciplinary effort consisting of a team of experienced surgeon, anesthesiologist, pediatrician, urologist, oncogynecologist, laboratory personell, blood bank as well as intensive care unit staff is vital for optimal management of the patients and fetus. ${ }^{11}$ Placenta percerta is responsible for up to $70 \%$ cesarean hystrectomies. Excessive blood loss is a major concern for cesarean hystrectomies, hence blood products should always be available for such cases. Hunter $\mathrm{T}$, Kleiman, set a routine protocol: cross matched for at least 10 units of packed red blood cells, 4 unit of fresh frozen plasma and 10 packs of platelets, before opting this type of cases due to increased chances of bleeding during the delivery. ${ }^{8}$ Autologous blood salvage device have proved safe and the use of these device may be a valuable adjunct during the surgery, ${ }^{12}$ in a case where the blood products are unavailable or shortage of blood products. Gallus et al. states that autologus blood salvage is quick, inexpensive and no cross matching is required. ${ }^{13}$ However the major drawback is the introduction of fetal hemoglobin into the mother's blood stream. Several other techniques to decrease blood loss and bleeding controls are also described in literature such as manual compression or cross clamping the aorta, oxytocin administration, hemodilution, bilateral iliac artery occlusion/embolization and Factor VIIa administration etc. $^{1,2,8,13}$ Pneumatic compression stocking should be placed pre operatively and should be maintained until the patients is fully ambulatory. The patients is this case reports received $3800 \mathrm{ml}$ red blood cells, $2200 \mathrm{ml}$ fresh frozen plasma and 20 units cryoprecipitate, antibiotics and vigorous fluid infusions because the patient underwent hemorrhagic shock. Several effective management options of such case have been described in literature but the most appropriate management remains controversial. Generally, the recommended management of such case is planned or emergency preterm cesarean hysterectomies with placenta left in situ because removal of the placenta is associated with significant hemorrhage morbidity. However, this approach might not be suitable for first line of management in women who have a strong desire for future fertility. The choice of incision should be made on basis of the patient's body habits and history of previous incision. The use of a midline vertical incision should be considered because it provides sufficient exposure if hysterectomy become necessary. A classic uterine incision, often transfundal may be necessary to avoid the placenta and allow delivery of the baby but we performed modified cesarean section with an incision being slight high above the previous scar on uterus and latter we did subtotal hysterectomy with placenta left in situ due to uncontrollable severe hemorrhage. If the patient have strong desire of future pregnancy and bleeding is not very severe and have normal coagulation status conservative approach such as interventional radiological procedure, methotrexate have been also described in the literature. The placenta is partially resected to minimize its size or complete placenta left in situ but reported cases of subsequent successful pregnancy in patients treated with this approach are rare and found to be high risk of sepsis and post-operative hemorrhage, needing for emergency hysterectomies.

There is a limited literature describing the ideal anesthesia preference for a patient with known placenta previa and suspected placenta accreta, increta, or percreta. Regional or General anesthesia can be used for the anesthetic management of such patients, ${ }^{14}$ both techniques having advantages as well as disadvantages. Regional anesthesia may be associated with decreased blood loss, decrease necessity for hysterectomy to control maternal hemorrhage and improved fetal outcome. ${ }^{15}$ This is mainly due to secondary response to sympathectomy that occurs with an initation of regional anesthesia, leading to decrease sympathetic tone and decrease arterial blood pressure hence decreased blood loss. ${ }^{14}$ While the literature supports that there is an increased blood loss in patients with placenta previa, placenta accreta or placenta percreta during cesarean section with use of general anesthesia. ${ }^{14,16}$ This is mainly due to increase sympathetic tone and increased arterial blood pressure leading to increased blood loss. However, if there is active bleeding or the patient is unstable, general anesthesia is the choice for maintaining airway, breathing and circulation ${ }^{17,18}$ and if there is no active bleeding and the patients is hemodynamically stable regional anesthesia is the choice. The patient in our case had severe hemorrhage and the 
patient underwent hemorrhagic shock so we converted regional anesthesia to general anesthesia.

\section{CONCLUSIONS}

The purpose of this paper is to increase awareness of central placenta previa with placenta percreta invading bladder, because the incidence is likely to rise substantially in near future due to increased number of cesarean sections, curettages and advanced maternal age and understanding its risk factor, presentation, diagnosis, management and choice of anesthesia .Central placenta previa with placenta percreta invading bladder is a very rare obstetrical condition with a high mortality due to severe hemorrhage. The extravillous trophoplast invades completely to the myometrium reaching to bladder due to absence or deficiency of Nitabuch's layer. We should always suspect placenta percreta invading bladder if there is placenta previa with history of previous cesarean section. Management of central placenta previa with placenta percreta invading bladder is a team work. Caesarean hysterectomy is considered best option for managing such cases. General anesthesia is the choice if the patient is hemodynamically unstable and there is heavy bleeding.

\section{Funding: No funding sources Conflict of interest: None declared Ethical approval: Not required}

\section{REFERENCES}

1. Kuczkowski KM. Anesthesia for the repeat cesarean section in the parturient with abnormal placentation: what does an obstetrician need to know? Arch Gynecol Obstet. 2006;273(6):319-21.

2. Oyelese Y, Smulian JC. Placenta previa, placenta accreta, and vasa previa. Obstet Gynecol. 2006;107(4):927-41.

3. Jaraquemada JMP, Pesaresi M, Nassif JC, Hermosid S. Anterior placenta percreta: surgical approach, hemostasis, and uterine repair. Acta Obstet Gynecol Scand. 2004;83(8):738-44.

4. Tantbirojn P, Crum CP, Parast MM. Pathophysiology of placenta creta: the role of decidua and extravillous trophoblast. Placenta. 2008;29(7):639-45.

5. Yoshino O, Osuga Y, Hirota Y, Koga K, Hirata T, Yano T, et al. Endometrial stromal cells undergoing decidualization down regulate their properties to produce proinflammatory cytokines in response to interleukin-1 beta via reduced p38 mitogen-activated protein kinase phosphorylation. J Clin Endocrinol Metab. 2003;88(5):2236-41.

6. Ng MK, Jack GS, Bolton DM, Lawrentschuk N. Placenta percreta with urinary tract involvement: the case for a multidisciplinary approach. Urology. 2009;74(4):778-82.

7. Clark SL, Koonings PP, Phelan JP. Placenta previa/accreta and prior cesarean section. Obstet Gynecol. 1985;66(1):89-92.

8. Hunter T, Kleiman S. Anaesthesia for caesarean hysterectomy in a patient with a preoperative diagnosis of placenta percreta with invasion of the urinary bladder. Can J Anesth. 1996;43(3):246-8.

9. LeMaire WJ, Louisy C, Dalessandri K, Muschenheim F. Placenta percreta with spontaneous rupture of an unscarred uterus in the second trimester. Obstet Gynecol. 2001;98(5):927-9.

10. Comstock $\mathrm{CH}$. Antenatal diagnosis of placenta accreta: a review. Ultrasound Obstet Gynecol. 2005;26(1):89-96.

11. Eller AG, Bennett MA, Sharshiner M, Masheter C, Soisson AP, Dodson M, et al. Maternal morbidity in cases of placenta accreta managed by a multidisciplinary care team compared with standard obstetric care. Obstet Gynecol. 2011;117:331-7.

12. ACOG Practice Bulletin No.76. Postpartum hemorrhage. Obstet Gynecol. 2006;108:1039-47.

13. Gallos G, Redai I, Smiley RM. The role of the anesthesiologist in management of obstetric hemorrhage. Semin Perinatol. 2009;33(2):116-23.

14. Parekh N, Husaini SW, Russell IF. Caesarean section for placenta praevia: a retrospective study of anaesthetic management. $\mathrm{Br} \mathrm{J}$ Anaesth. 2000;84(6):725-30.

15. Abboud TK, Gerard C, Go A, Zhu J. Anesthesia for placenta previa at women's hospital: a 3 year survey. Twenty-fifth Annual Meeting of the Society for Obstetric Anesthesia and Perinatology. Palm Springs, CA; 1993: 19. Cited by: Wali A, Suresh MS, Gregg AR. Antepartum hemorrhage. In: Datta $\mathrm{S}$, eds. Anesthetic and Obstetric Management of High-Risk Pregnancy. 3rd ed. New York, NY: Springer-Verlag; 2004: 87-109.

16. Hong JY, Jee YS, Yoon HJ, Kim SM. Comparison of general and epidural anesthesia in elective cesarean section for placenta previa totalis: maternal hemodynamics, blood loss and neonatal outcome. Int J Obstet Anesth. 2003;12(1):12-6.

17. Plaat F. Anaesthetic issues related to postpartum haemorrhage (excluding antishock garments). Best Pract Res Clin Obstet Gynecol. 2008;22(6):1043-56.

18. Wali A, Suresh MS, Gregg AR. Antepartum hemorrhage. In: Datta S, eds. Anesthetic and Obstetric Management of High-Risk Pregnancy. 3rd ed. New York, NY: Springer-Verlag; 2004: 87-109.

DOI: $10.18203 / 2320-1770 . i j r \operatorname{cog} 20150110$

Cite this article as: Banu $\mathrm{H}$, Hui JW, Hui L, Hua L. Central placenta previa with placenta percreta partially invading bladder: a case report. Int J Reprod Contracept Obstet Gynecol 2015;4:859-62. 